Industrial Crops and Products

April 2018, Volume 114 Pages 52-58

http://dx.doi.org/10.1016/j.indcrop.2018.01.065

http://archimer.ifremer.fr/doc/00427/53875/

(C) 2018 Elsevier B.V. All rights reserved.

\title{
Recommended flax fibre density values for composite property predictions
}

\author{
Le Gall Maelenn ${ }^{1}$, Davies Peter ${ }^{1,{ }^{*}}$, Martin Nicolas ${ }^{2}$, Baley Christophe ${ }^{2}$ \\ ${ }^{1}$ IFREMER, Centre Bretagne, Marine Structures Laboratory, 29280 Plouzané, France \\ ${ }^{2}$ University of South Brittany, IRDL, 56100 Lorient, France \\ * Corresponding author : Maelenn Le Gall, email address : peter.davies@ifremer.fr
}

\begin{abstract}
:
Density is one of the fundamental properties of fibres which reinforce polymer matrix composites, and is used both to estimate composite weight and to evaluate fibre content for property predictions. For traditional composites, reinforced by glass or carbon fibres, unique density values are well known for a particular fibre grade and provide reliable fibre content estimations and composite property predictions. However, this is not the case for natural fibres. This paper first reviews published density values for flax (Linum usitatissimum L.) fibres and describes the limitations of techniques used to measure fibre density. Significant variations in published densities are found, which can be related to the measurement method. New data quantify the influence of measurement technique, fibre extraction route, moisture content, and reinforcement geometry. Values obtained by buoyancy are around $10 \%$ lower than those obtained by pycnometry. Finally the consequences of measured density variations on property estimations for long fibre composites are discussed; volume fraction values calculated from buoyancy provide more accurate tensile modulus values compared to experimental values than those from gas pycnometry; the former are recommended for predictive use.
\end{abstract}

\section{Highlights}

A set of data containing measurements on well-defined flax fibres by pycnometer and Archimedes principle. An analysis of the influence of differences in flax density values on composite properties. Density values from weighing in air and fluid density should be used, rather than pycnometer values, in making composite property predictions.

Keywords : Density, Flax, Archimedes, Pycnometer, Volume fraction, Tensile modulus 


\section{Introduction}

Flax fibre density values can be found in various text books, Table 1, in a similar way to the values given for other composite reinforcements such as glass and carbon fibres.

Table 1. Density of fibre reinforcements

The range of values given in Table 1 for glass fibre densities is directly related to differences in compositions of the different fibre grades. For example, for E-glass fibres a common value is 2.58 whereas high strength and corrosion resistant glass are a little lighter and heavier respectively (Dwight, 2000).

For carbon fibres there is a significant difference between the two families of precurseur; for polyacrylonitrile (PAN) based fibres, which represent the majority of carbon fibre reinforcements for composites, density of most commercial high strength fibres is around 1.8 (Morgan, 2005). For pitch based carbon fibres the densities are higher, generally around 2.1 (Morgan, 2005)

If the glass or carbon fibre grade is known, then the values indicated by suppliers can in general be used with confidence to estimate composite fibre contents. For natural fibres the situation is rather different. If potential users of flax fibres refer to textile fibre handbooks they will find a typical value for flax fibre density (Table 1), usually around 1.5. However, the recent development of natural fibre composite applications has resulted in a large increase in the number of studies of these materials, Table 2, and if results from these are examined the single-value approach used for glass and carbon (once the grade has been specified) is more difficult to justify. Published values range from 1.36 to 1.57 , a difference of around $20 \%$.

Table 2. Published flax fibre density values

The first observation is that the origins of the values quoted are not always given; when they are provided then either immersion or gas pycnometry tend to be favoured. Different techniques are used traditionally to measure fibre density, and these may not be suitable for natural fibres. A study by Truong et al (2009) identified five measurement methods for high performance fibre density, and discussed their application to natural fibres:

- Linear density and diameter calculation,

- Archimedes (buoyancy)

- Helium pycnometry

- Liquid pycnometry, and

- Density gradient column.

The first is included in an ASTM standard (ASTM,2007). It was used by Soykeabkaew et al (2004) and involves measuring the average diameter of 100 fibres and the weight of 10 fibres of known lengths, and calculating the density by assuming a circular cross-section. Clearly the latter assumption is not correct for natural fibres. Figure 1 shows the cross section of a flax fiber bundle after fine polishing, indicating a polygonal cross-section for fax fibres. The values obtained by Soykeabkaew et al (2004) were very low, around 0.29 for a fibre bundle diameter of $210 \mu \mathrm{m}$. An improvement could be made by measuring the true sections on polished cross-sections, as Summerscales et al (2010) have done 
for jute fibres, but again this is a very time-consuming approach, and the natural shape variability along the fibres will not be taken into account unless a large number of observations are made.

Figure 1. Example of section through flax fibres in a bundle in a young plant, showing large lumens. Image corresponds to a section $(160 \times 300) \mu \mathrm{m}^{2}$.

Buoyancy methods are simple to perform and widely used for composite density measurement but care is needed in choosing the immersion fluid. For example, ASTM D792 (2013) recommends weighing in water, but cellulose-based fibres such as flax are quite hydrophilic. They normally contain a few percent by weight of moisture and this can increase significantly during immersion. Le Duigou et al (2017) have shown using environmental scanning electron microscopy that flax fibres absorb water and swell as relative humidity increases. This method is therefore not adapted to natural fibres unless an alternative immersion medium is used. Facca et al. (2006) suggested mercury as an alternative, while a recent study by Amiri et al. (2017) examined the influence of the immersion medium and recommended soybean oil rather than distilled water. This is not a new debate; there has been considerable controversy over the values of density for cellulose fibres. Early measurements by Davidson are often cited, dating from 1927 (Davidson,1927). He measured the density of cellulose in toluene, helium and water. The density values in helium for cotton fibres (1.57) were intermediate between those in toluene (1.55) and water (1.61), though differences between the three are smaller than those noted in Table 2.

Hermans and Vermaas (1946) argued that density is a macroscopic concept and that if a macroscopic body contains pores only an apparent value can be determined. Stamm provided additional discussion (Stamm, 1950), presenting results from density measurements in benzene which were close to values from X-ray analysis.

The condition of the sample will also affect the density measurements, although this is a physical difference rather than an artefact of measurement. Nevertheless careful attention must be paid to moisture content in natural fibre specimens when measurements are made. Baley et al (2005) showed that drying of fibres at $105^{\circ} \mathrm{C}$ for 12 hours resulted in a weight loss of $8.7 \%$.

Gas and liquid pycnometers have been used for some time to determine density of polymers, and a standard test method exists (ISO, 1999). Pycnometers measure the volume of a sample of known weight, by measuring the volume of either displaced inert gas or liquid; the pressures measured on filling the sample chamber then discharging the gas or liquid into a second empty chamber enable computation of the sample solid phase volume.

Finally, gradient columns have been used traditionally to determine the density of bulk polymers, and again standard methods are available (ASTM, 2010), but the same concerns about the immersion medium noted above will apply.

Truong et al (2009) showed results from measurements made using the first three methods on oilseed flax fibres. Data showed very large differences in density, from 1.5 with a helium pycnometer to over 2.5 using the linear density and diameter method. The authors recommended two methods, based on a number of criteria including accuracy (with respect to a published density range of 1.4 to 1.6), safety, cost and convenience; they favoured either buoyancy, using canola oil as the fluid, or helium pycnometry. 
A second observation on Table 2 is that the variation in pycnometer measurements is quite small. Given the number of parameters which may contribute to variations this is quite surprising, as these include residual moisture and the influence of extraction conditions; the composite reinforcements available commercially generally include fibre bundles held together by pectines, Figures 1 and 2 . The density value obtained does not therefore only correspond to the cellulose, which composes 65 to $85 \%$ of the fibres and has a density of around 1.5, but includes the contributions of all the other components, in particular lignin and hemicelluloses. Load transfer between fibers is performed by shared lamella between fibers. To extract the fibers, it is necessary to damage the lamella during retting and scutching operations (Baley et al., 2014). In the flax plant stems, fibers tied together by their pectic junctions within a bundle structure constitute a type of composite material. The stress is transferred to the reinforcing fibers through their junctions that may be considered to be pectic polymers. The junctions consist of two main types of pectins (homogalacturonan and rhamnogalacturonan) and are present in two morphological domains; the middle lamella between the primary cell walls of two neighboring fibers and the corners of the tricellular junctions of three fibers (Baley et al., 2014).

Figure 2. SEM photo of fibre bundle in a commercial unidirectional composite reinforcement.

The density of pectins is believed to be similar to that of cellulose, around 1.5 to 1.6 (Salbu et al., 2010), suggesting that the presence of pectins is unlikely to cause large variations in density.

Another factor which may influence values is the geometry of samples. Flax fibres have a central lumen, as shown in Figure 1, more or less well developed according to growing conditions. Access to this by a fluid to measure volume will depend on the fluid viscosity but also on the fibre length. The transverse and the longitudinal dimensions lie in the range of 5-30 $\mu \mathrm{m}$ and 5-80 $\mathrm{mm}$, respectively (van Dam \& Gorshkova , 2003, Batra, 1998). The average length of flax fibre is $25 \mathrm{~mm}$ [31]

Measurements of the proportion of lumen in the fibre cross section by Charlet et al (2007) suggest that the lumen represents on average 2.7 to $4 \%$ of the cross-section and rarely exceeds $8 \%$ for fibres taken from mature plants. Whether or not the measuring fluid enters the lumen can therefore change the apparent volume and hence the density measurement by up to $8 \%$.

Lewin (2010) cites work by Sinha et al who suggest that it is the presence of porosity which causes variations in density values; they indicate $10.7 \%$ porosity in flax fibres resulting in an apparent density of 1.38 but a true density of 1.50 . Shah (2014) also highlighted this point.

In order to provide complementary data to clarify the role of these parameters a series of tests has been performed using the same helium pycnometer equipment on samples of flax fibre reinforcements. Glass fibres have also been tested, to serve as a reference. Results from these tests will be described below, and then the consequences of density variations for composite properties will be discussed.

\section{Materials and methods}

The baseline material tested here is a commercially available unidirectional flax reinforcement fabric of nominal areal weight $400 \mathrm{~g} / \mathrm{m}^{2}$, Figure 3 . It is intended for hand lay-up, infusion and resin transfer 
moulding of composites. It consists of unidirectional non-twisted rovings with no surface treatment, held together by weft flax fibres. Density measurements were only performed on the warp fibres extracted from the fabric.

Figure 3. Photo of unidirectional fabric

Additional fibre samples were used to examine the density at different steps of the fibre extraction process, from the plant to the retted, scutched fibres. These were provided by von Robaeys Freres, a flax fibre producer in Northern France.

For comparison, the same measurements were made on E-glass fibre samples. Two E-glass grades were characterized, first a reinforcement produced for filament winding, reference Vetrotex R099 2400 tex, then a grade used for infusion moulding, Advantex ${ }^{\mathrm{TM}}$ SE20.

An AccuPyc II 1340 gas pyncnometer from Micromeritics ${ }^{\mathrm{TM}}$ using helium was employed for most of the density measurements here. This equipment uses 10 purge cycles (about 10 minutes) and then makes 30 measurements over one hour. Values given here are the average of the 30 measurements. Calibration was performed with a steel sphere before each series.

Additional measurements were made using the Archimedes principle, by weighing in air and in ethanol with a Sartorius ${ }^{\mathrm{TM}}$ balance.

All tests were performed in a temperature and humidity controlled laboratory and all samples were kept under those conditions for at least 24 hours before measurements unless otherwise noted. At least 5 samples were tested for each condition.

\section{Results}

Three series of tests have been performed: In the first, both flax and glass fibre commercial reinforcements have been tested, in order to examine the influence of test conditions (amount of fibre, form of fibre, drying) on the results and to quantify the measurement variability. Tests on 10 different samples were performed. Then one of these samples was tested 5 times.

The second series examines material effects for flax fibres. First, the influence of the part of the plant from which fibres were taken was examined. Then, differences in retting and processing on density were studied. The aim of this series was to provide upper and lower limits on density measurements in order to study the consequences of using a single density value for flax fibres.

The third series compares measurements made with two different techniques, weighing in air and water and gas pycnometry, on similar specimens.

\section{a) Influence of test conditions.}

Table 3 shows results from a series of tests in which samples from the same reinforcement batches (the same glass bobbin and the same flax reinforcement fabric) were tested in a helium pycnometer to quantify repeatability. The volume of material tested was kept similar for all these samples (around $0.75 \mathrm{~g}$ ).

Table 3. Repeatability of pycnometer density measurements, glass and flax fibres. 
These results indicate that the variability of the measurements on both materials when samples are taken from a single batch are quite similar, and that measurements are repeatable.

The influence of the sample condition was then examined. First, the fibre lengths were reduced by cutting but the same overall sample mass was retained. The results are shown in Table 3, labelled "Finely cut" (less than $10 \mathrm{~mm}$ long). For both fibres the difference with or without cutting is less than $1 \%$.

Then the amount of fibres tested was increased (without cutting). The equipment suppliers recommend that the capsule is two-thirds filled, this is the "Standard" amount, and the values in Table 3 correspond to this proportion. A second series was then tested in which sample quantity was increased by compacting to force more fibres into the capsule compared to the standard amount.

Compacting the samples has very little effect on glass fibre density $(<1 \%)$ but results in a small drop in flax density, of around $3 \%$. This suggests that compacting flax fibres results in a larger apparent volume, presumably as it limits access to parts of the sample in the pycnometer. The lower transverse modulus of flax fibres compared to glass may also result in physically closing the lumen during compaction.

A third series was then performed, using the recommended filling amount without cutting, in which the same samples were tested first as-received then tested again after drying in an oven at $40^{\circ} \mathrm{C}$ to constant weight. The "Dried" values in Table 3 show the results. The effect on glass density is again small, less than $1 \%$. The flax fibre density decreases after drying as expected; there is a density drop after the weight of water has been removed of around $4 \%$.

Figure 4 summarizes these results for the glass and flax fibres.

Figure 4. Influence of test conditions on measured density values, a) glass and b) flax fibres.

b) Material variability

In the second series of tests samples were taken from plants of the same Alyzée grade from the same field but subjected to different retting periods. The degree of retting affects the separation of the fibres in the flax fibre extraction process. The influence of retting on fibre properties has been examined by Martin et al (2013) previously and these samples were taken from the same batches of fibres. Sixteen days is believed to be the optimal duration for these plants, Figure 5. Figure 6 shows how the degree of retting affects the surface aspect and the bundle division of these fibres.

Figure 5. Scutched samples taken from the field after different degrees of retting, from left to right 1, 5, 9, 14, 16, 19 days. Scale bar $10 \mathrm{~cm}$.

Figure 6. Electron microscope images of surfaces of fibres at two magnifications, after 1 day retting (left column, images $a$ and $c$ ), and 19 days, (right column, images $b$ and $d$ ). 
Tests were performed using the standard sample quantities and without cutting, with the same pycnometer as the one used for the series described previously. Results are shown in Table 4.

Table 4. Influence of retting conditions and measurement method on density.

The influence of retting time on density after scutching is small, less than $2 \%$, and less significant than the difference due to compaction of the samples.

c) Comparison with other measurement techniques

In a third series of tests, the previous gas pycnometer results from the three batches of fibres with different degrees of retting were compared to results obtained on samples from the same batches obtained by weighing in air and during immersion in ethanol, Table 4. Samples of glass (a different glass grade to that examined previously) and flax from both the $400 \mathrm{~g} / \mathrm{m}^{2}$ reinforcement and a scutched Aramis fibre were also analyzed, Table 5.

Table 5. Comparison between immersion and pycnometer for glass and flax fibres.

The density values for these glass fibres, measured by pycnometer, are similar to those given in Table 3 , even though the glass grade is different; the Advantex fibre tested here is a boron-free E-CR glass, and it has a particular coating. Values from immersion are slightly lower by about $4 \%$, it is not clear why, but the difference may be caused by the coating being more porous to gas than to ethanol. Thermogravimetric analysis (TGA) indicated that the coating represents about $4 \%$ by weight.

For the five flax samples (Tables 4 and 5) the immersion method results in flax density values which are significantly lower than those measured by the pycnometer, by around $10 \%$. This is in agreement with the trend from published values for flax from different sources shown in Table 2. It is probably due to the latter measuring lower sample volumes because of deeper infiltration of the gas into the lumen and other porosities compared to the liquid. Variability is also higher for the weighing method.

\section{Discussion}

The results presented previously illustrate the difficulty in establishing density values for natural fibres compared to inorganic materials. The main factor which affects the density is the measurement method. Values from gas pycnometry measured here are systematically higher than those determined by weighing during immersion, by up to $12 \%$. Secondary factors which may explain variability are moisture content and sample preparation (cutting and compaction).

In order to examine the consequences of these variations in density for the analysis of composite properties a sensitivity study has been performed, to examine the influence of uncertainty in fibre density on predicted long fibre composite properties. The influence of the measured variations in fibre density using the gas pycnometer and immersion methods described in the Results section above has been evaluated.

Figure 7 shows an example of the potential error in estimated properties when composite density is used to determine flax fibre volume fraction (Figure 7a) and then to estimate tensile modulus in the fibre direction (Figure 7b) using a law of mixtures. If a typical nominal value for flax density found in handbooks (Gordon, 2001) is used (1.54) the fibre volume fraction and the tensile modulus may be significantly underestimated when compared to density values obtained by the immersion method. 
For example, a measured composite density of 1.30 could indicate a volume fraction of around $30 \%$ with a fibre density of 1.54 but closer to $40 \%$ using 1.45 . This translates into estimated composite modulus values from 19 to $25 \mathrm{GPa}$.

Figure 7. a) Estimated fibre volume fraction versus flax composite density for different fibre densities, matrix density taken to be 1.2, no porosity. b) Influence of fibre content on composite axial modulus,

(based on matrix modulus $3 \mathrm{GPa}$, flax fibre modulus $57 \mathrm{GPa}$ ).

Given the size of this difference it is interesting to compare estimations with experimental data. Tests were performed on unidirectional hackled Aramis flax reinforced composites during a round robin exercise for the CELC (European Flax and Hemp Association) (Bensadoun et al, 2017). For one set of data produced at IFREMER the density of the epoxy matrix resin was determined by helium pycnometry to be 1.17 , and its modulus was measured to be $3.0 \mathrm{GPa}$. The average fibre modulus was measured on samples from the same batch to be $40.2 \mathrm{GPa}$. The composite densities were measured with the same gas pycnometer. From these data and assuming no porosity it is now possible to estimate the composite tensile modulus in the fibre direction, using either a fibre density of 1.534 (measured by gas pycnometer) or 1.39 from immersion in ethanol to calculate volume fractions. Table 6 shows the modulus estimations and the measured values.

Table 6. Predicted and measured values of axial modulus (strain range $0-0.1 \%$ ), unidirectional

$$
\text { flax/epoxy }
$$

These results clearly indicate a better prediction of the composite modulus with the lower value of fibre density. This suggests that while the gas pycnometer may provide a better indication of the intrinsic material density, by filling all the voids and the lumen, the method based on Archimedes principle by weighing in a liquid may be more representative of the resin impregnation process which is used to produce composites. The viscosity of the matrix resin prevents it from filling small pores, and hence weighing in an appropriate fluid provides a better value to be used in micromechanics estimation of composite properties. More work is needed to clarify this, and recent work to characterize the wetting of plant fibres by resins [e.g. LeDuigou et al, 2017) may help to clarify the physical interactions. It should also be noted that tensile stress-strain plots for flax composites tend to be non-linear (Bensadoun et al, 2017), here only the initial slope has been examined.

The two measurement techniques, weighing in air and in a liquid and gas pycnometry, have advantages and limitations. The former is widely available; most laboratories have precision scales. However, care is needed in the choice of immersion liquid and in avoiding air bubbles which can have a strong influence on measurement accuracy. The gas pycnometer is more expensive, and requires an inert gas supply but it involves less handling and is easier to calibrate. The choice of method depends on the end use of the data, and this work indicates that the more traditional weighing method provide more appropriate data for flax fibres intended as reinforcement of composites.

\section{Conclusion}

The density of flax (and other natural fibres) cannot be characterized by a unique value in the same way as glass and carbon fibres. Apparent density is strongly dependent on the measurement method, weighing in air and in a liquid results in values lower by up to $12 \%$ than values from a helium 
pycnometer. Variable moisture content adds another parameter which must be carefully controlled. The consequences of this uncertainty in fibre density values cannot be neglected, as it has a direct influence on estimations of fibre properties. The density values from weighing in air and fluid appear to give a better correlation with measured composite modulus values than the higher densities determined by gas pycnometry. It is therefore recommended that the former be used to determine densities for prediction of composite properties.

\section{References}

Amiri A., Triplett Z., Moreira A., Brezinka N., Alcock M., Ulven C.A., 2017, Standard density measurement method development for flax fiber, Ind. Crops Prod. 96, 196-202

ASTM D1577 (2007), Standard Test Methods for Linear Density of Textile Fibers, American Society for Testing and Materials

ASTM D1505 (2010), Standard Test Method for Density of Plastics by the Density-Gradient Technique ASTM D792 (2013), Standard Test Methods for Density and Specific Gravity (Relative Density) of Plastics by Displacement.

Baley C., 2002, Analysis of the flax fibres tensile behaviour and analysis of the tensile stiffness increase. Compos. Part A: Appl. Sci.Manuf., 33, 7, 939-48.

Baley C., Morvan C., Grohens Y.; 2005, Influence of the Absorbed Water on the Tensile Strength of Flax Fibers. Macromol. Symp. 222, 195-201.

Baley C., Le Duigou A., Bourmaud A., Davies P., Nardin P., Morvan C., 2014, Reinforcement of polymers by flax fibres: The role of interfaces, in Bio-based Composites for High-Performance Materials: From Strategy to Industrial application. Editors: W. Smitthipong, R. Chollakup, M. Nardin, Taylor and Francis, Boca Raton, Florida, USA, 87-112

Batra S., 1998, Handbook of Fibre Science and Technology. Volume IV, Fibre Chemistry, Marcel Dekker, New York, USA.

Bensadoun F., Verpoest I., Baets J., Müssig J., Graupner N., Davies P., Gomina M., Kervoelen A., Baley C., 2017, Impregnated fibre bundle test for natural fibres used in composites, J. Reinf. Plast. \& Compos., 36, 13, 942-957.

Chafei S., Khadraoui F., Boutouil M., Gomina M., 2014, Optimizing the formulation of flax fiberreinforced cement composites, Constr. \& Build. Mater., 54, 659-664.

Charlet K., Baley C., Morvan C., Jernot J.P., Gomina M., Bréard J., 2007,Characteristics of Hermes flax fibres as a function of their location in the stem and properties of the derived unidirectional composites, Compos. Part A: Appl. Sci.Manuf., 38, 1912-1921.

Davidson G.F., 1927, The specific volume of cotton cellulose, J. Text. Inst. 18, 175-186. 
Dicker M.P.M., Duckworth P.F., Baker A.B., Francois G., Hazzard M.K., Weaver P.M., 2014, Green composites: A review of material attributes and complementary applications, Compos. Part A: Appl. Sci.Manuf., 56, 280-289.

Dwight D.W.,2000, Glass Fiber Reinforcements, chapter 1.08 in Comprehensive composite materials, editor A. Kelly, Elsevier, Oxford, UK.

Facca A.G., Kortschot M.T., Yan N, 2006, Predicting the elastic modulus of natural fiber reinforced thermoplastics, Compos. Part A: Appl. Sci.Manuf., 37, 10, 1660-71.

Gordon Cook J., 2001, Handbook of Textile Fibres, Vol. 1, Natural Fibres, Woodhead Publishing, Cambridge, England, (first published 1959).

Hearle J.W., 2001, editor, High performance fibres, Glass Fibres, Chapter 6, F.R. Jones, Woodhead publishing, Cambridge, England.

Hermans P.H., Vermaas D., 1946, Density of cellulose fibers. I. Introduction and Experiments on the penetration of liquids into dry cellulose, J. Polym. Sci., 1, 8, 149-155.

ISO 1183-3 (1999) Plastics - Methods for determining the density of non-cellular plastics -Part 3: Gas pyknometer method.

Le Duigou A., Kervoelen A., Le Grand A., Nardin M., Baley C., 2014, Interfacial properties of flax fibreepoxy resin systems: Existence of a complex interphase. Compos. Sci. Technol., 100; 152-7.

Le Duigou A., Merotte J., Bourmand A., Davies P., Belhouli K., Baley C., 2017, Hygroscopic expansion: A key point to describe natural fibre/polymer matrix interface bond strength, Compos. Sci. Technol., 151, 228-233.

Lewin M., 2010, Handbook of Fiber Chemistry, $3^{\text {rd }}$ edition, CRC Press, Boca Raton, Florida, USA.

Madsen B., Lilholt H., 2003, Physical and mechanical properties of unidirectional plant fibre composites - an evaluation of the influence of porosity, Compos. Sci. Technol. 63, 1265-72.

Martin N., Mouret N., Davies P., Baley C., 2013, Influence of the degree of retting of flax fibers on the tensile properties of single fibers and short fiber/polypropylene composites, Ind. Crops Prod., 49, 755-767.

Mitsubishi datasheet, http://mccfc.com/pitch-fiber/ (accessed $20^{\text {th }}$ January 2018).

Morgan P., 2005, Carbon fibers and their composites, Taylor and Francis, Boca Raton, Florida, USA, pp795-797.

Müssig J., Hughes M., 2012, Reinforcements: Fibres, Chapter 2 in Flax and Hemp Fibres: a natural solution for the composites industry, CELC/JEC publication, Paris, France.

Salbu L., Bauer-Brandl A., Tho I., 2010, Direct Compression Behavior of Low- and High-Methoxylated Pectins, AAPS PharmSciTech, 11, 1.

Shah D.U., 2013, Characterisation and optimisation of the mechanical performance of plant fibre composites for structural applications. PhD thesis, University of Nottingham. 
Soykeabkaew N., Supaphol P., and Rujiravanit R., 2004, Preparation and characterization of jute- and flax-reinforced starch-based composite foams. Carbohydr. Polym., 58, 53-63.

Stamm A.J., 1950, Specific volume of native cellulose, Text. Res. J., Sept, 631-636

Summerscales J., Dissanayake N.P.J., Virk A.S., Hall W., 2010, A review of bast fibres and their composites. Part 1 - Fibres as reinforcements, Compos. Part A: Appl. Sci.Manuf., 41, 1329-1335.

Toray datasheet T700S, http://www.toraycfa.com/pdfs/T700SDataSheet.pdf, (accessed $20^{\text {th }}$ January 2018).

Truong M., Zhong W., Boyco S., Alcock M., 2009, A comparative study on natural fibre density measurement, J. Text. Inst., 100, 6, 525-529.

Van Dam J.E.G., Gorshkova T.A., 2003,Fiber Formation. Encyclopedia of Applied Plant Sciences. Elsevier; doi:10.1016/B0-12-227050-9/00046-6. 
Table 1. Density of fibre reinforcements

\begin{tabular}{lcc}
\hline Fibre reinforcement & Density values & Reference \\
\hline Glass (range) & $2.46-2.74$ & Hearle,2001 \\
e.g. E-glass & 2.58 & Dwight, 2000 \\
e.g. S2-glass & 2.46 & Dwight, 2000 \\
e.g. E-CR (Electrical/Chemical Resistance) & 2.72 & Dwight, 2000 \\
Carbon PAN-based (range) & $1.68-1.91$ & Morgan, 2005 \\
e.g. T700 & 1.80 & Toray \\
Carbon pitch-based (range) & $1.90-2.20$ & Morgan, 2005 \\
e.g. K63712 & 2.12 & Mitsubishi \\
Flax (typical data) & 1.54 & Gordon, 2001 \\
\hline
\end{tabular}


Table 2. Published flax fibre density values

\begin{tabular}{|c|c|c|c|}
\hline Fibre type & Density values & Measurement method & Reference \\
\hline Flax & $1.43-1.55$ & & Lewin, 2010 \\
\hline Flax & $1.4-1.52$ & & Mussig \& Hughes, 2012 \\
\hline Flax & 1.53 & Immersion, ethanol & Baley, 2002 \\
\hline Flax scutched, & 1.34 & Immersion, ethanol & Martin et al., 2013 \\
\hline Flax tow & 1.37 & & Martin et al., 2013 \\
\hline Flax, cut & 1.54 & Helium pycnometry & Chafei et al;, 2014 \\
\hline Flax & $1.42-1.52$ & & Dicker et al., 2014 \\
\hline Flax yarn & 1.54 & $\begin{array}{l}\text { Immersion, water, } \\
\text { corrected for lumen }\end{array}$ & Madsen \& Lilholt , 2003 \\
\hline Flax yarn & 1.57 & Helium pycnometry & Shah, 2013 \\
\hline \multirow[t]{2}{*}{ Linseed flax } & $1.41-1.47$ & Immersion, different oils & Amira et al, 2017 \\
\hline & 1.49 & Helium Pycnometry & Amira et al, 2017 \\
\hline
\end{tabular}


Table 3. Repeatability of pycnometer density measurements, and influence of test conditions, glass and flax fibres.

\begin{tabular}{lcc}
\hline Material and condition & 10 different samples & $\begin{array}{c}5 \text { tests on the same } \\
\text { sample }\end{array}$ \\
\hline Glass fibre, standard & $2.548(0.006)$ & $2.557(0.004)$ \\
Finely cut & $2.561(0.009)$ & \\
Compacted larger sample (2x mass) & $2.565(0.001)$ & \\
Dried & $2.546(0.007)$ & \\
& & \\
Flax fibre, standard & $1.585(0.008)$ & \\
Finely cut & $1.599(0.012)$ & \\
Compacted larger sample (2x mass) & $1.543(0.003)$ & \\
Dried & $1.514(0.007)$ & \\
\hline
\end{tabular}

(Standard deviations in brackets) 
Table 4. Influence of retting conditions and measurement method on density.

\begin{tabular}{llll}
\hline $\begin{array}{l}\text { Sample retting time, } \\
\text { days }\end{array}$ & $\begin{array}{l}\text { Pycnometer standard } \\
\text { cut sample }\end{array}$ & $\begin{array}{l}\text { Pycnometer } \\
\text { compacted, cut. }\end{array}$ & $\begin{array}{l}\text { Weighing in air and in } \\
\text { ethanol }\end{array}$ \\
\hline 1 & $1.559(0.007)$ & $1.523(0.002)$ & $1.392(0.065)$ \\
9 & $1.535(0.006)$ & $1.508(0.001)$ & $1.405(0.018)$ \\
16 & $1.567(0.006)$ & $1.507(0.002)$ & $1.430(0.017)$ \\
\hline
\end{tabular}

(Standard deviations in brackets) 
Table 5. Comparison between immersion and pycnometer for glass and flax fibres.

\begin{tabular}{lcc}
\hline Sample & Weighing in air and in ethanol & Gas pycnometer \\
\hline Glass Advantex SE20 & $2.472(0.030)$ & $2.588(0.007)$ \\
Flax 400g/m² UD reinforcement & $1.415(0.011)$ & $1.571(0.004)$ \\
Flax Aramis scutched & $1.392(0.009)$ & $1.534(0.001)$ \\
\hline
\end{tabular}

(Standard deviations in brackets) 
Table 6. Predicted and measured values of axial modulus (strain range $0-0.1 \%$ ), unidirectional flax/epoxy

\begin{tabular}{lccccc}
\hline Sample & 1 & 2 & 3 & 4 & 5 \\
\hline Measured composite density & 1.308 & 1.287 & 1.294 & 1.296 & 1.305 \\
Experimental modulus, GPa & 16.5 & 20.7 & 17.2 & 18.3 & 15.0 \\
& & & & & \\
Prediction, $\rho_{\mathrm{f}}=1.392, \mathrm{GPa}$ & 17.9 & 19.4 & 19.4 & 20.9 & 19.7 \\
Prediction, $\rho_{\mathrm{f}}=1.534, \mathrm{GPa}$ & 12.3 & 13.0 & 12.9 & 13.6 & 13.2 \\
\hline
\end{tabular}




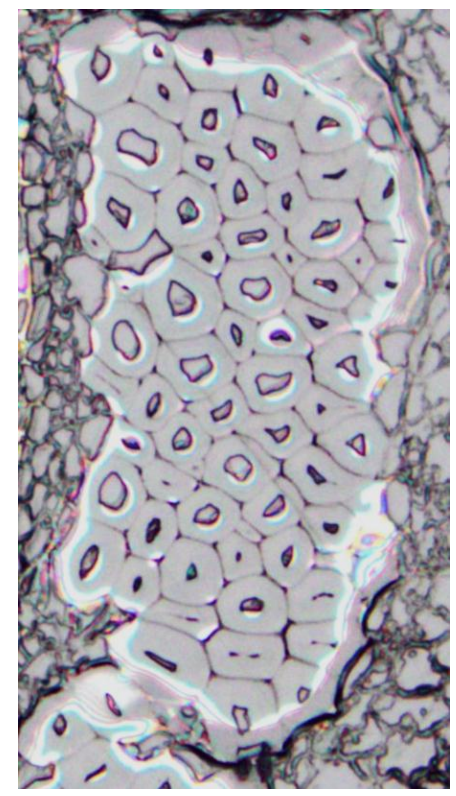

Figure 1. Example of section through flax fibres in a bundle in a young plant, showing large lumens. Image corresponds to a section $(160 \times 300) \mu \mathrm{m}^{2}$. 


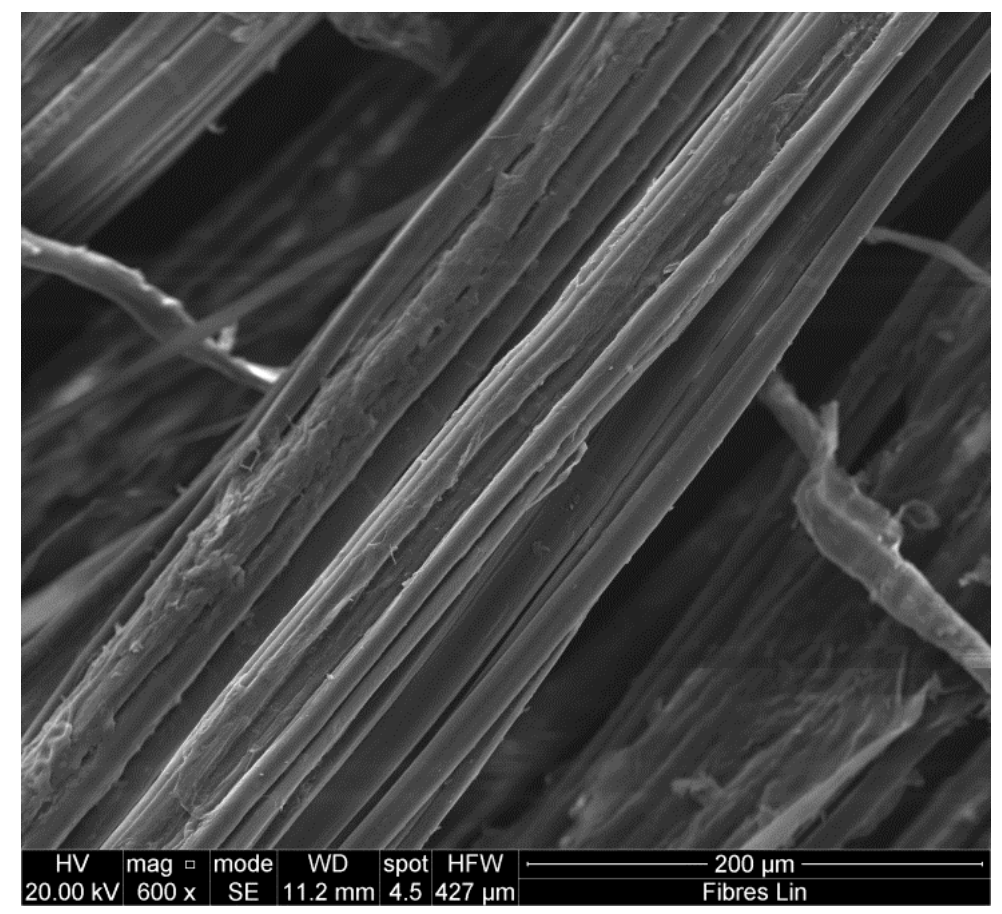

Figure 2. SEM photo of fibre bundle in a commercial unidirectional composite reinforcement. 


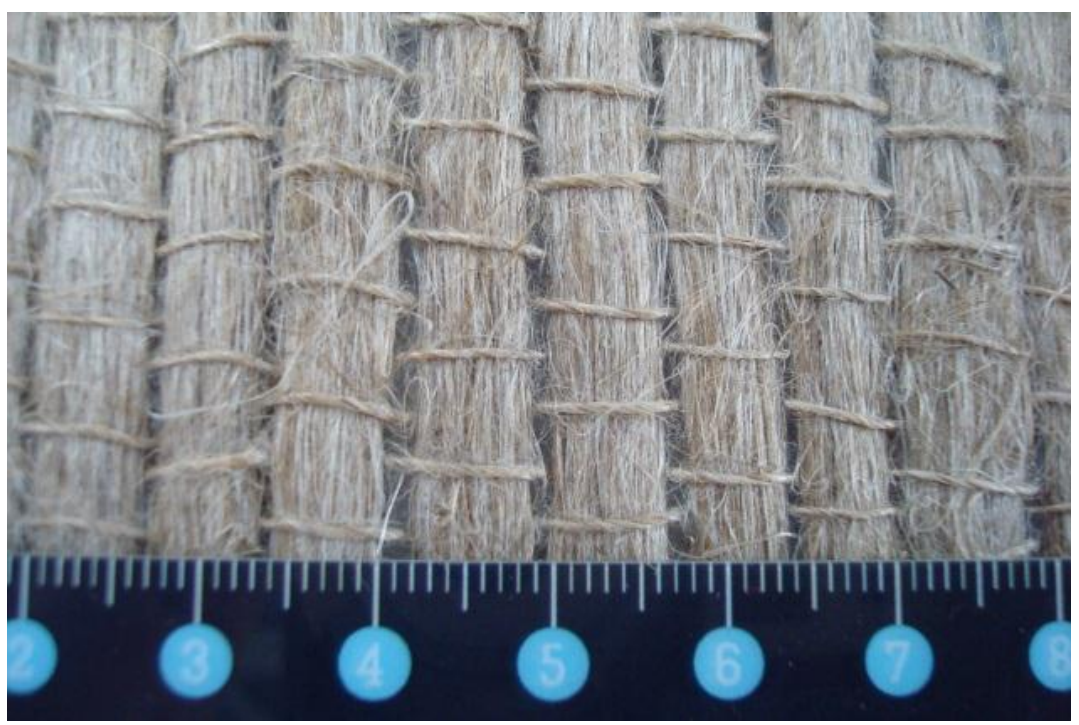

Figure 3. Photo of unidirectional fabric 


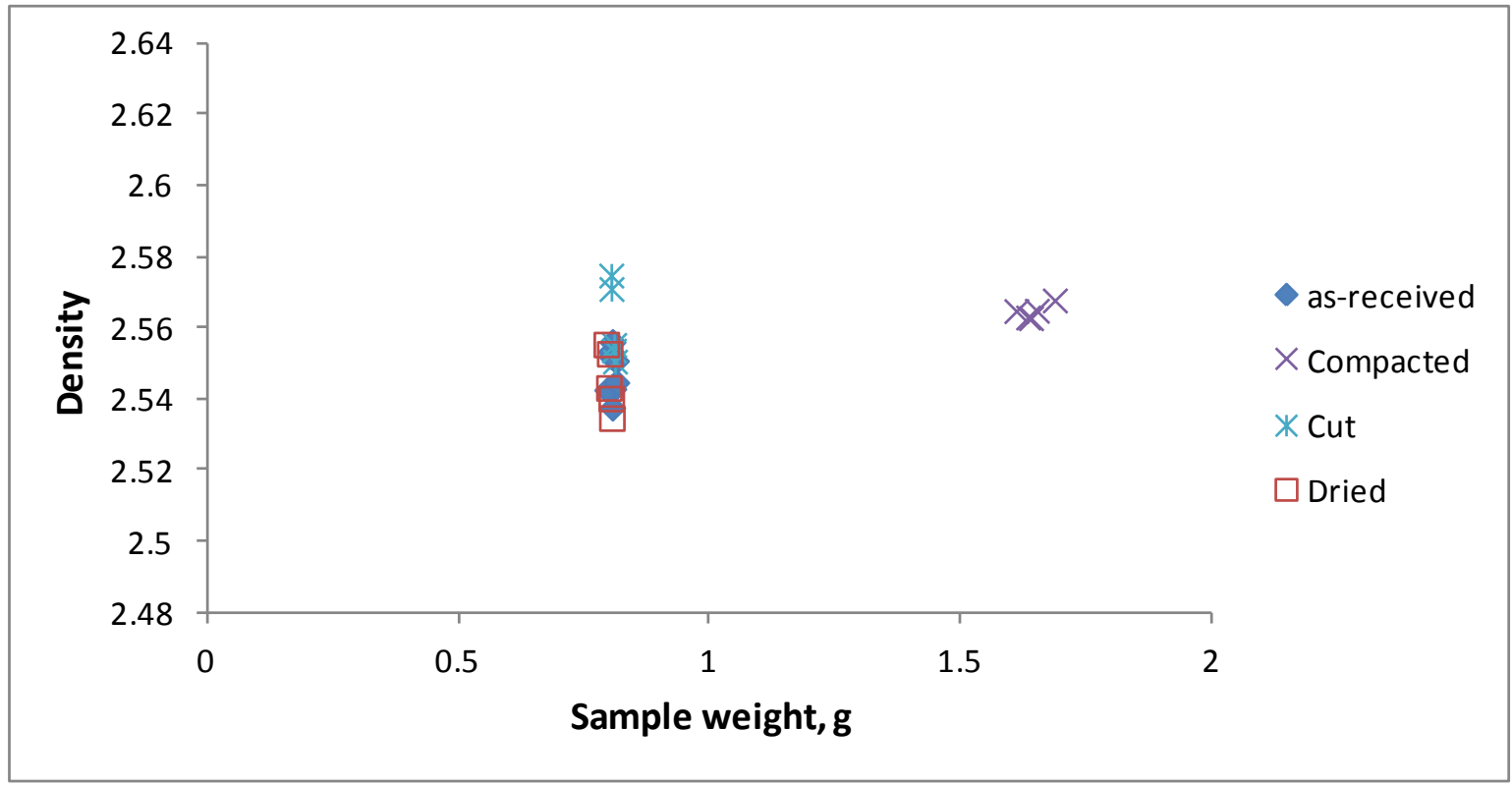

(a)

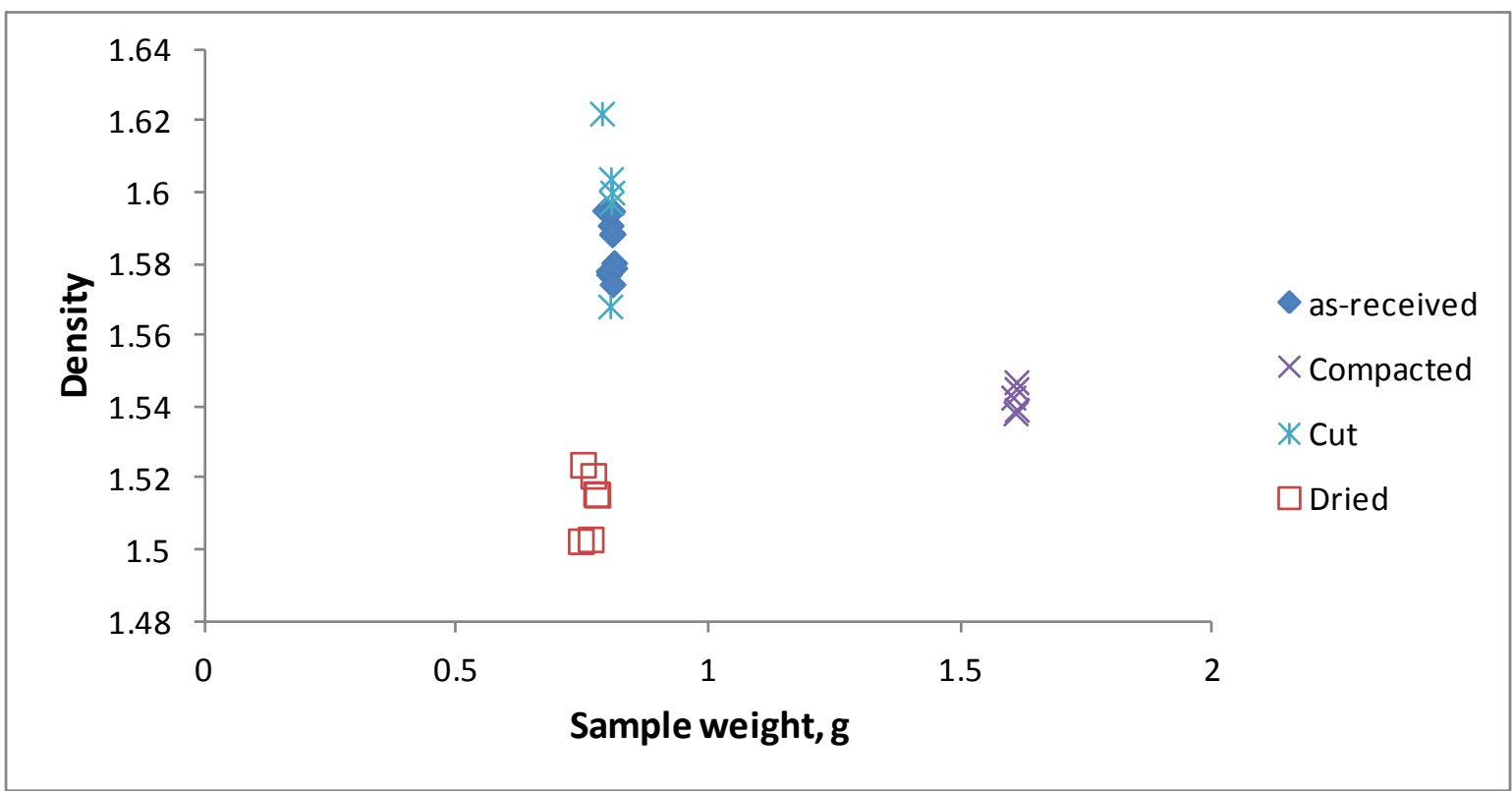

(b)

Figure 4. Influence of test conditions on measured density values, a) glass and b) flax fibres. 


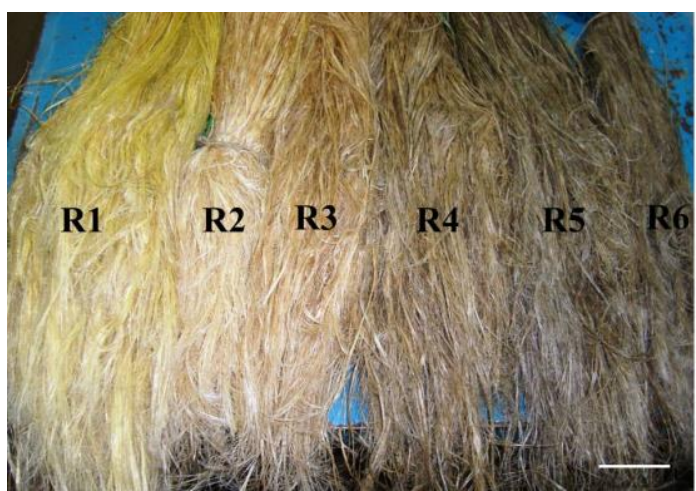

Figure 5. Scutched samples taken from the field after different degrees of retting, from left to right $1,5,9,14,16,19$ days. Scale bar $10 \mathrm{~cm}$. 


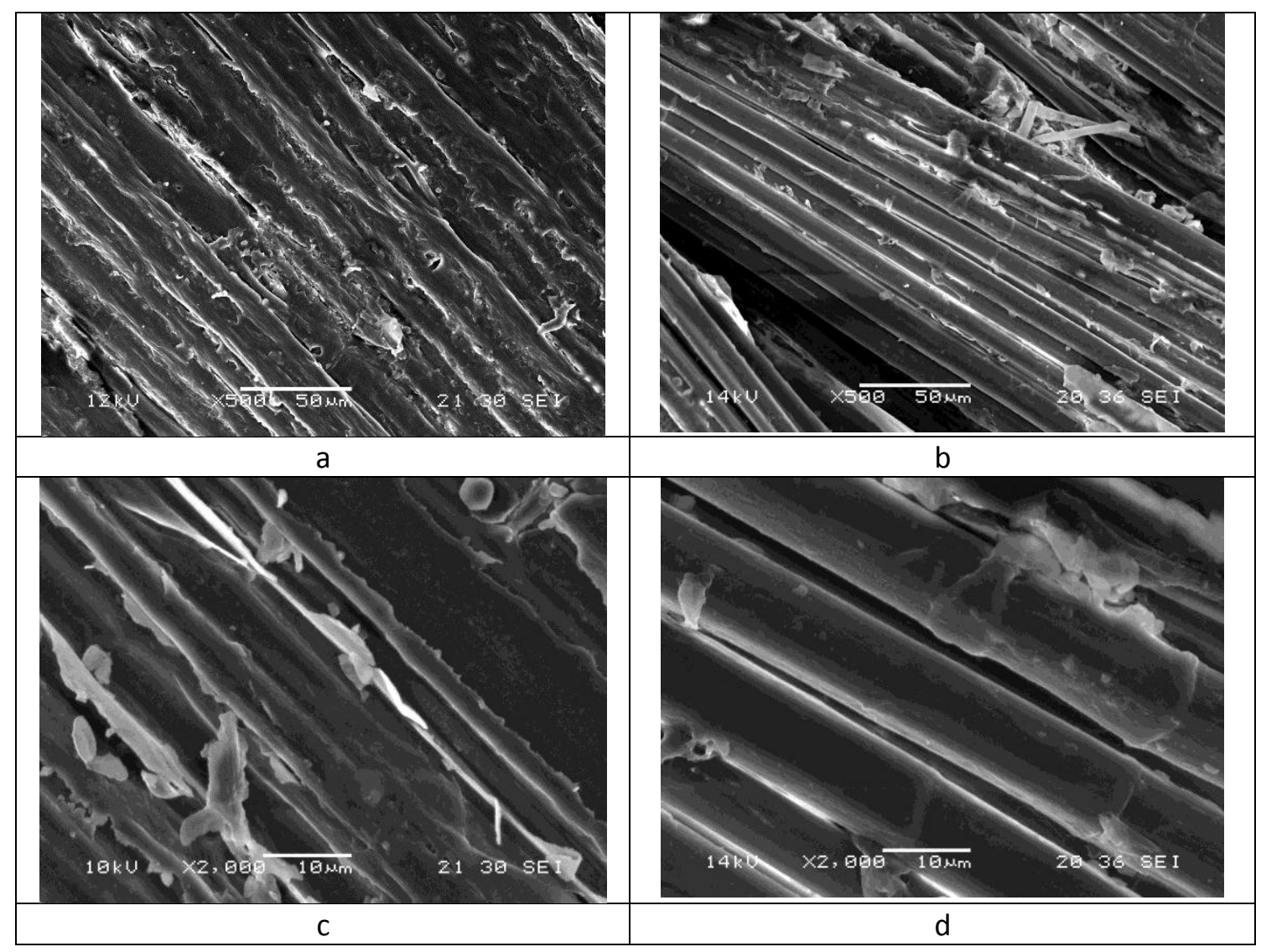

Figure 6. Electron microscope images of surfaces of fibres at two magnifications, after 1 day retting (left column, images a and c), and 19 days, (right column, images b and d). 


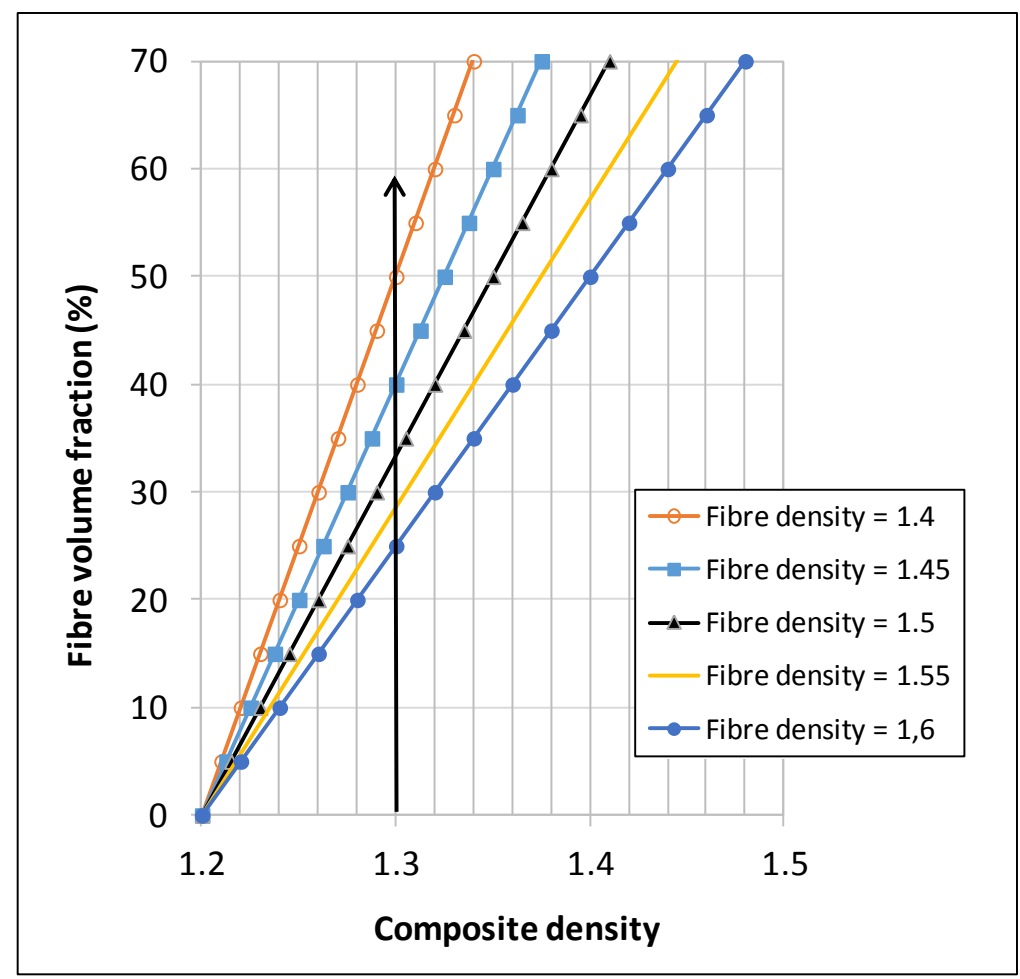

(a)

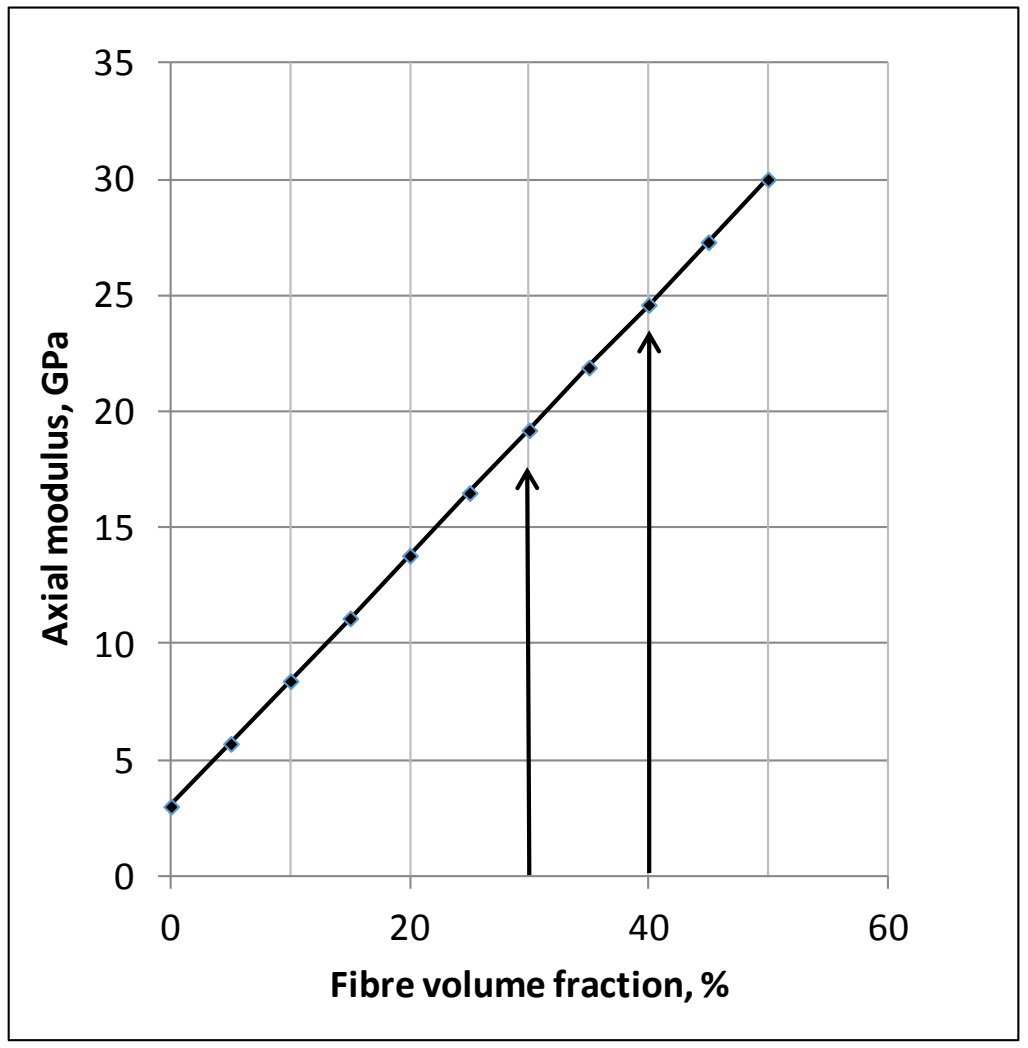

(b)

Figure 7. a) Estimated fibre volume fraction versus flax composite density for different fibre densities, matrix density taken to be 1.2 , no porosity. b) Influence of fibre content on composite axial modulus, (based on matrix modulus $3 \mathrm{GPa}$, flax fibre modulus $57 \mathrm{GPa}$ ). 